\title{
Molecular phylogeny of the Microsporidia: ecological, ultrastructural and taxonomic considerations
}

\author{
Charles R. Vossbrinck ${ }^{1}$ and Bettina A. Debrunner-Vossbrinck ${ }^{2}$ \\ ${ }^{1}$ Department of Soil and Water, The Connecticut Agricultural Experiment Station, 123 Huntington Street, New Haven, \\ Connecticut 06511, USA; \\ ${ }^{2}$ School of Health Sciences, Quinnipiac University, 275 Mount Carmel Avenue, Hamden, Connecticut 06518, USA
}

Key words: Microsporidia, phylogeny, taxonomy, classification, systematics

\begin{abstract}
The Microsporidia are a group of obligate intracellular parasites, now thought to be derived fungi. Presented here is a comparative small subunit rDNA (ssrDNA) analysis of 125 species of Microsporidia (sequences obtained from GenBank). This analysis shows that groups or clades are formed based largely on habitat and host. This result is supported by comparative molecular analyses of the past decade, and indicates that structural and ultrastructural characters are unreliable for distinguishing among higher-level microsporidian taxa. Our findings indicate the presence of five major clades of Microsporidia which group according to habitat. We present three new classes of Microsporidia based on natural phylogenetic groupings as illustrated by the ssrDNA analysis: Aquasporidia, Marinosporidia and Terresporidia. The names of the proposed classes reflect the habitat of each group. The class Aquasporidia, found primarily in freshwater habitats, is a paraphyletic group consisting of three clades. The Marinosporidia are found in hosts of marine origin and the Terresporidia are primarily from terrestrial environments.
\end{abstract}

A unique feature of the Microsporidia is the long, coiled polar filament present in the spore, which is used to inject the sporoplasm into the host cell upon spore germination. The polar filament is thought to evert, penetrating the host cell and pulling the sporoplasm into the host cell. This ability of the Microsporidia has apparently allowed these parasites to diverge into numerous animal hosts from many of the animal phyla. This apomorphic feature, and the unique diplokaryon arrangement of the nuclei (in many species) clearly define the Microsporidia structurally.

Microsporidia, like all organisms, are classified using common characters which appear as different character states. In the Microsporidia an example of a character used for classification is the nuclear condition, with uninucleate and diplokaryotic character states. Other examples of characters used in the classification of the Microsporidia include the number of coils in the polar filament around the periphery of the spore and the thickness of the polar filament (with isofilar and anisofilar character states). Development of taxonomies is an iterative process in which it is decided which characters change state rapidly and can be used to distinguish genera, species and populations and which characters change state slowly and can be used to distinguish higher levels such as class, order and family. Unfortunately, the characters which are used to determine the higher levels of classification in the Microsporidia (number of nuclei/cell, presence of a membrane surrounding the parasite (sporophorous vesicle), and type of nuclear division) appear to be characters which change states quickly at the genus, species and popula- tion levels. Comparative analyses of small subunit ribosomal (ssrDNA) sequence data show that the use of ultrastructural features for taxonomic divisions of the Microsporidia is untenable, and indicate that the Microsporidia can instead be divided into groups which reflect habitat and host.

To determine a plausible phylogeny for any group of organisms, a data set has to be made which includes each organism and all of the common characters and character states which can be identified for the group. After this data set is complete, a phylogenetic analysis can be conducted.

Four fundamentally different types of phylogenetic analyses are available: distance methods, parsimony analysis, maximum likelihood analysis (Swofford 2002) and Bayesian analysis (Huelsenbeck et al. 2001).

Distance methods are the least computationally intensive and involve calculating a matrix of differences of character states between each pair of taxa. Even with a large number of taxa a distance tree can be rapidly constructed. Each pair of taxa are then connected based on similarity (unpaired group mean analysis, UPGMA) and in the case of neighbour-joining analysis, calculations are made to adjust, as far as possible, for differences in evolutionary rates among taxa.

Maximum parsimony analysis involves the construction of every possible tree (the branch and bound

An earlier version of this paper was presented at the NATO Advanced Research Workshop "Emergent Pathogens in the 21st Century: First United Workshop on Microsporidia from Invertebrate and Vertebrate Hosts", held in České Budějovice, Czech Republic, July 12-15, 2004.

Address for correspondence: C.R. Vossbrinck, Department of Soil and Water, The Connecticut Agricultural Experiment Station, 123 Huntington Street, New Haven, CT 06511, USA. Phone: ++1 203974 8522; Fax: ++1 203974 8502; E-mail: charles.vossbrinck@po.state.ct.us 
routine will shorten the process while still guaranteeing finding the shortest tree) and places the character states for each character on each tree. The number of evolutionary steps required for each tree is determined and the tree which requires the fewest evolutionary steps is considered to be the best. Maximum parsimony analysis is therefore a minimum homoplasy (the tree described by the fewest convergent character states) analysis. While distance methods give a single tree, maximum parsimony methods can give more than one tree with the same number of evolutionary steps (more than one shortest tree). In addition, it is useful to see if trees which are one or two steps longer than the shortest tree, based on molecular data, might fit better with taxonomies based on non-molecular characters. This capability was implemented into the latest version of PAUP (http://paup.csit.fsu.edu/downl.html).

Maximum likelihood analysis is by far the most computationally intensive algorithm. The problem reduces to computing the probability of a particular set of sequences on a given tree and maximizing this probability over all evolutionary trees (Felsenstein 1981). It involves finding the evolutionary tree which yields the highest probability of containing the observed data. Each tree examined involves considerable computation; this method is good for data sets with a small number of taxa or for testing subsets of data where the resolution of a relationship among a few taxa is difficult.

Bayesian analysis (not yet included in the PAUP package), like maximum likelihood analysis, is a probabilistic method which (in the case of Bayesian inference) calculates a posteriori, the probability of finding a tree based on a set of assumptions. It has recently become a popular method (Mr. Bayes program; http://morphbank.ebc.uu.se/mrbayes/) for evaluating evolutionary trees as it seems to do a good job with tested data sets (Murphy et al. 2001) but as a purely mathematical approach claims no mechanistic basis.

Almost all editors now require a bootstrap analysis with any phylogenetically based tree. This computer algorithm randomly samples the sequence data and generates trees based on these sampled subsets of data. Typically one hundred trees will be generated (using any of the above procedures) and a consensus tree is produced showing the percentage of trees which gave a particular topology on the tree. Branch points on the tree with high consensus values (in the range of 95 to $100 \%$ ) are thought, with fair certainty, to contain those taxa. This gives the reader a feel for the data in terms of which parts of the tree are better resolved and which areas need more data or more analysis.

As discussed above, all of these methods require a data set containing characters with character states for the Microsporidia being analysed. Larsson (1986, 1988, 1999) has made several bold attempts to make such an analysis. Larsson (1986) makes a gallant effort at gathering and listing characters and character states for the purpose of constructing a phylogeny based on "traditional" (morphological and developmental) features. In his review papers, Larsson clearly illustrates, with light and electron micrographs, the structural and ultrastructural features which could be used in differentiating various taxa of Microsporidia. Larsson (1986) lists 12 characters for 64 taxa covering a much broader group of Microsporidia (mostly different genera) than those considered here. In addition, Larsson (1986) presents some of the first attempts at a phylogenetic analysis of Microsporidia using such characters and character states. From a phylogenetic point of view, Larsson should be highly commended for his tremendous effort to develop characters and character states for the Microsporidia. In his 1999 review article Larsson lists 14 characters for the "identification of Microsporidia" but develops no phylogenetic tree. He attributes the failure to develop an accurate tree to having incomplete descriptions for many of the species and therefore an incomplete data set. The more likely explanation is that none of these characters clearly defines any higher level taxa.

Issi (1986) also presents an important review of microsporidian features with a database consisting of 68 genera and 11 characters. The text of this publication has been translated into English by Professor Jerzy J. Lipa and is available through the Division of Microsporidia from the Society of Invertebrate Pathology. Issi (1986) presents detailed illustrations of microsporidian characters and proposes a taxonomic scheme based on Weiser (1977). Issi (1986) also mentions studies showing similarities between the Microsporidia and yeast cells with respect to the type of nuclear division (acentriolar cryptic intranuclear pleuromitosis) and points out that the lamellar plates in the spindles of Microsporidia resemble those of yeast nuclei, but does not claim a connection between the Microsporidia and the Fungi.

Early classifications of the Microsporidia were developed based on characters which were visible with light microscopy (Balbiani 1882, Stempell 1909, Léger and Hesse 1922) and were attempts to separate the Microsporidia into logical groups. Over time more emphasis was placed on developing taxonomies which did not differ unreasonably from perceived evolutionary relationships (Hennig 1966). With the advent of the electron microscope, new ultrastructural characters, such as type of nuclear division, were described for the Microsporidia (Tuzet et al. 1971, Weiser 1977, Sprague 1977, Sprague et al. 1992). These ultrastructural characters were then incorporated into classifications of the Microsporidia (Sprague et al. 1992).

Higher-level taxonomic classifications of the Microsporidia differ in the placement of the Chytridiopsidae and Hessidae. Weiser (1977) includes the Metchnikovellidae, Chytridiopsidae and Hessidae in the Metchnikovellidea ("primitive" Microsporidia) while Sprague (1977, 1982) places the Chytridiopsidae and Hessidae with the "higher" Microsporidia. The "higher" Micro- 
sporidia are then divided into two groups based on the presence (Pansporoblastina) or absence (Apansporoblastina) of an external cover around the sporoblast (the pansporoblast, Tuzet et al. 1971). Sprague et al. (1992) introduce a different classification system, based on whether the species is diplokaryotic at some point in the life cycle (Dihaplophasea) or uninucleate throughout its life cycle (Haplophasea). The Dihaplophasea are further separated into those in which the diplokaryon is formed through meiosis (Meiodihaplophasida) and those in which the diplokaryon is formed through nuclear dissociation (Dissociodihaplophasida).

\section{MATERIALS AND METHODS}

All sequences presented in Table 1 are available from the United States National Center for Biotechnology Information DNA sequence repository and shared with the European Molecular Biological Laboratory. Sequences were aligned using the alignment program CLUSTAL_X.

Table 1. Microsporidian and three outgroup sequences used for ssrDNA phylogenetic analysis.

\begin{tabular}{|c|c|}
\hline Organism & GenBank Acc. No. \\
\hline Amblyospora bracteata & AY090068 \\
\hline Amblyospora californica & U68473 \\
\hline Amblyospora canadensis & AY090056 \\
\hline Amblyospora cinerei & AY090057 \\
\hline Amblyospora connecticus & AF025685 \\
\hline Amblyospora crenifera & AY090061 \\
\hline Amblyospora excrucii & AY090043 \\
\hline Amblyospora ferocious & AY090062 \\
\hline Amblyospora indicola & AY090051 \\
\hline Amblyospora khaliulini & AY090045 \\
\hline Amblyospora opacita & AY090052 \\
\hline Amblyospora salinaria & U68474 \\
\hline Amblyospora stictici & AY090049 \\
\hline Amblyospora stimuli & AF027685 \\
\hline Amblyospora weiseri & AY090048 \\
\hline Amblyospora sp. 1 & AY090053 \\
\hline Amblyospora sp. 2 & AY090055 \\
\hline Amblyospora sp. 3 & AJ252949 \\
\hline Ameson michaelis & L15741 \\
\hline Antonospora scoticae & AF024655 \\
\hline Basidiobolus ranarum & AY635841 \\
\hline Bacillidium vesiculoformis & AJ581995 \\
\hline Bacillidium sp. & AF104087 \\
\hline Berwaldia schaefernai & AY090042 \\
\hline Brachiola algerae & AF069063 \\
\hline Bryonosema plumatellae & AF484690 \\
\hline Caudospora palustris & AF132544 \\
\hline Caudospora simulii & AY973642 \\
\hline Conidiobolus coronatus & AF296753 \\
\hline Culicospora magna & AY090054 \\
\hline Culicosporella lunata & AF027683 \\
\hline Cystosporogenes legeri & AY233131 \\
\hline Cystosporogenes operophterae & AJ302320 \\
\hline Dictyocoela cavimanum & AJ438960 \\
\hline Dictyocoela deshayesum & AJ438961 \\
\hline
\end{tabular}

Dictyocoela muelleri

Dictyocoela duebenum

Dictyocoela berillonum

Dictyocoela gammarellum

Edhazardia aedis

Encephalitozoon cuniculi

Encephalitozoon hellem

Encephalitozoon intestinalis

Encephalitozoon lacertae

Enterocytozoon bieneusi

Endoreticulatus schubergi

Endoreticulatus bombycis

Flabelliforma magnivora

Flabelliforma montana

Glugea americanus

Glugea anomala

Glugea atherinae

Glugea stephani

Glugoides intestinalis

Gurleya daphniae

Gurleya vavrai

Hazardia milleri

Hazardia sp.

Heterococcus pleurococcoides Heterosporis anguillarum

Heterosporis $\mathrm{sp}$

Hyalinocysta chapmani

Ichthyosporidium giganteum

Intrapredatorus barri

Janacekia debaisieuxi

Kabatana takedai

Larssonia obtusa

Loma acerinae

Loma salmonae

Loma embiotocia

Loma sp.

Marssoniella elegans

Microgemma caulleryi

Microgemma sp.

Microsporidium prosopium

Nadelspora canceri

Nosema apis

Nosema bombi

Nosema bombycis

Nosema carpocapsae

Nosema ceranae

Nosema furnacalis

Nosema granulosis

Nosema oulemae

Nosema portugal

Nosema pyrausta

Nosema spodopterae

Nosema trichoplusiae

Nosema tyriae

Nosema vespula

Nucleospora salmonis

Nucleospora sp.

Oligosporidium occidentalis

Ordospora colligata

Orthosomella operophterae
AJ438956

AF397404

AJ438957

AJ438958

AF027684

L39107

L39108

L39113

AF067144

L07123

L39109

AY009115

AJ302318

AJ2052962

AF056014

AF044391

U15987

AF056016

AF394525

AF439320

AF394526

AF090067

AF090066

AJ579335

AF387331

AF356225

AF483837

L39110

AY013359

AY090070

AF356222

AF394527

AJ252951

U78736

U78815

AF104081

AY090041

AY033054

AJ252952

AF151529

AY958070

X73894

AY008373

L39111

AF426104

U26533

U26532

AJ011833

U27359

AF033316

AY 958071

AY211392

U09282

AJ012606

U11047

U78186

AF186007

AF495379

AF394529

AJ302317 


$\begin{array}{ll}\text { Ovipleistophora mirandellae } & \text { AF356223 } \\ \text { Paranosema grylli } & \text { AY305325 } \\ \text { Paranosema locustae } & \text { AY305324 } \\ \text { Paranosema } \text { whitei } & \text { AY305323 } \\ \text { Parathelohania anophelis } & \text { AF027682 } \\ \text { Parathelohania obesa } & \text { AF090065 } \\ \text { Pleistophora anguillarum } & \text { U47052 } \\ \text { Pleistophora mirandellae } & \text { AF104085 } \\ \text { Pleistophora ovariae } & \text { AJ278955 } \\ \text { Pleistophora typicalis } & \text { AF044387 } \\ \text { Polydispyrenia simulii } & \text { AY090069 } \\ \text { Pseudoloma neurophilia } & \text { AF322654 } \\ \text { Pseudonosema cristatellae } & \text { AF484694 } \\ \text { Schroedera plumatellae } & \text { AY135024 } \\ \text { Spraguea lophii } & \text { AF033197 } \\ \text { Tetramicra brevifilum } & \text { AF364303 } \\ \text { Thelohania contejeani } & \text { AF492593 } \\ \text { Thelohania parastaci } & \text { AF294779 } \\ \text { Thelohania solenopsae } & \text { AF031538 } \\ \text { Trachipleistophora hominis } & \text { AJ002605 } \\ \text { Trichonosema algonquinensis } & \text { AY582742 } \\ \text { Trichonosema pectinatellae } & \text { AF484695 } \\ \text { Trichotuzetia guttata } & \text { AY326268 } \\ \text { Vairimorpha } \text { sp. } & \text { AF031539 } \\ \text { Vairimorpha cheracis } & \text { AF327408 } \\ \text { Vairimorpha imperfecta } & \text { AJ131645 } \\ \text { Vairimorpha lymantriae } & \text { AF033315 } \\ \text { Vairimorpha necatrix } & \text { Y00266 } \\ \text { Vavraia culicis } & \text { AJ252961 } \\ \text { Vavraia oncoperae } & \text { X74112 } \\ \text { Visvesvaria acridophagus } & \text { AF024658 } \\ \text { Vittaforma corneae } & \text { L39112 } \\ \text { Weiseria palustris } & \text { AF132544 } \\ & \\ & \end{array}$

\section{RESULTS AND DISCUSSION}

\section{A Molecular Classification of the Microsporidia based on ssrDNA analysis}

Fig. 1 is a phylogenetic tree of the 125 species of Microsporidia for which relatively complete small subunit rDNA (ssrDNA) sequences are available. Fig. 1 shows a consensus tree resulting from 20,000 bootstrap replicates using neighbour-joining analysis. Fig. 2 is a maximum parsimony tree showing the same basic relationships among the 5 major groups except that the rooting of the parsimony tree separates clade $\mathrm{V}$ into two separate groups. The parsimony tree given was one of 30 shortest trees generated. Since the 30 shortest trees differed only in relationships within the Nosema/Vairimorpha and Dictyocoela groups, the parsimony consensus tree is not shown as it does not show relative distances among taxa. Considering the large number of taxa analysed, the trees resulting from these two very different methods are remarkably similar. The relative positions of the three proposed classes are the same for Figs. 1 and 2. The parsimony tree of Fig. 2 gives a distinct rooting but the trichotomy of Fig. 1 indicates that the rooting of this tree is still in question.
The ssrDNA gene has not been sequenced for any of the "primitive" Microsporidia from the family Metchnikovellidae, so this analysis includes only the "higher Microsporidia". The Metchnikovellidae are considered primitive (Sprague 1977) because they lack polaroplasts and have a very short, thick polar filament. The metchnikovellids are parasites of gregarines (which in turn are parasites of polychaete annelids) and this modification of the polar filament could represent a derived state for parasitizing a specialised host. At this time it is not known whether the short polar filament of the Metchnikovellidae is a plesiomorphic (primitive) character, as Sprague's (1977) classification would suggest, or whether this character state has been secondarily derived (apomorphic) in response to the small host, as the classification of Tuzet et al. (1971) would imply. If the short polar filament is a plesiomorphic character then a Metchnikovella species would be an extremely important outgroup for the analysis of the phylum Microsporidia.

Due to recent reports that Microsporidia are derived fungi (Edlind et al. 1996, Keeling and Doolittle 1996) specifically related to the Zygomycota (Keeling et al. 2000), we selected two fungi, Basidiobolus ranarum and Conidiobolus coronatus from the family Entomophthoraceae in the Zygomycota, as outgroups. The yellow-green eukaryotic alga, Heterococcus pleurococcoides is also included as an outgroup. The analysis in Fig. 1 reveals clade V, members of the Class Aquasporidia, to be the sister group to the remaining "higher" Microsporidia. This placement agrees with the results of Canning et al. (2002), who used Bayesian inference and maximum likelihood analysis of ssrDNA from 44 species, with the zygomycote Basidiobolus ranarum as an outgroup. The Canning et al. (2002) analysis shows a group of Microsporidia (clades $\mathrm{G}$ and $\mathrm{H})$ primarily from freshwater habitats which appears to be the sister group to the remaining Microsporidia. Clades $\mathrm{G}$ and $\mathrm{H}$ correspond to clade $\mathrm{V}$ in Fig. 1. It has been shown previously (Vossbrinck et al. 2004a) for 82 species of Microsporidia that there is a correlation between phylogenetic group and habitat (freshwater, marine and terrestrial) for the three major groups of Microsporidia.

The phylogeny in Fig. 1 illustrates a number of points that have emerged over the past decade as a result of molecular analysis of the Microsporidia. Analysis of partial large subunit rRNA sequences (Baker et al. 1994) showed that the genus Nosema (defined as being diplokaryotic throughout the life cycle) was composed of a group of "true Nosema" as defined by the type species Nosema bombycis, and several additional groups of unrelated Nosema species including Nosema locustae (now Paranosema locustae), N. algerae (now Brachiola algerae) and $N$. kingi. This finding suggested that the character state of being diplokaryotic throughout the life cycle was not necessarily an indication of relatedness. 
The analysis also indicated that the Vairimorpha (based on the type species Vairimorpha necatrix) were the sister group to the "true" Nosema species. Baker et al. (1994) observed that the formation of octospores during the life cycle occurred in some species which clustered with the genus Nosema (as defined by N. bombycis) and did not occur in some species which clustered with the genus Vairimorpha (as defined by $V$. necatrix). Fig. 1 shows a mixture of Nosema (diplokaryotic throughout the life cycle) and Vairimorpha (octospores present at some point in the life cycle) species in two clades of the terrestrial Microsporidia. At the same time, primers for amplification of microsporidial ribosomal DNA were also being developed (Vossbrinck et al. 1993). Two primers (ss530F and 1s580R) were constructed to amplify a segment of DNA containing a large portion of the small subunit rDNA, the internal transcribed spacer (ITS) region and a portion of the large subunit rDNA. Vossbrinck et al. (1993) showed that restriction analysis of the resulting PCR products gave distinctive patterns, allowing differentiation among three isolates (Encephalitozoon hellem, Encephalitozoon cuniculi and Nosema corneum) from AIDS patients, showing clearly for the first time that E. hellem and E. cuniculi were two separate species. The ITS region was shown to be highly variable. Didier et al. (1996) found differences in this region among isolates of E. cuniculi corresponding to the host from which the strain was isolated. Attempts were made to standardise the primers for microsporidial rDNA amplification (Vossbrinck et al. 1993, Kent et al. 1996), but some species of Microsporidia did not amplify well in this region (ss530F to ls580R). As a result the small subunit rDNA ( $18 \mathrm{~F}$ to $1492 \mathrm{R}$ ), which was amplified successfully for the majority of the Microsporidia tested, became the standard sequence used for molecular analysis of microsporidial rDNA (Weiss and Vossbrinck 1999), excluding the variable internal transcribed spacer (ITS) region from the analysis.

Analysis of ssrDNA (Baker et al. 1995) again demonstrated the Vairimorpha/Nosema relationship and showed the Encephalitozoon species to be the sister group to the Vairimorpha/Nosema clade. Placement of the ultrastructural characters on the molecular tree revealed that characters such as nuclear condition, membrane surrounding the sporoblast, sporogony and chromosome cycle did not seem to be indicators of relatedness (Baker et al. 1995). The molecular analysis also indicated that Septata intestinalis was a member of the genus Encephalitozoon as originally described by Didier et al. (1991). Baker et al. (1997) proposed that the complex life cycles of Amblyospora (Andreadis 1985, Sweeney et al. 1985) may represent the plesiomorphic state for Microsporidia. Phylogenetic analysis indicated that the Amblyospora were a sister group to the remainder of the higher Microsporidia. The most parsimonious explanation for the ssrDNA phylogeny is that the ancestral microsporidian was aquatic and had a complex life cycle, and that groups with simpler life cycles represent losses of various life-cycle components. Sequencing of four additional Amblyospora and Amblyospora-like Microsporidia (Baker et al. 1998) showed a possible evolutionary correlation between Aedes and Culex hosts and Amblyospora parasites and between Anopheles hosts and Parathelohania parasites. Further work (Vossbrinck et al. 2004b) reinforced these results with additional examples of Amblyospora species which separated along the lines of Culex and Aedes/Ochlerotatus host clades. Small subunit rDNA sequence information was also used for the identification of intermediate hosts (Voss-brinck et al. 1998) by sequencing spores from possible copepod intermediate hosts and comparing these sequences to those obtained from spores from mosquito hosts.

The great discrepancies between the evolutionary relationships among the Microsporidia based on small subunit rDNA analysis and the published taxonomic designations based on morphological characters must be resolved. It is proposed here that taxonomic divisions of the Microsporidia consider phylogenetic relatedness and that major taxonomic divisions be based on habitat and host. Taxa are already being renamed based on their evolutionary relationships as determined by ssrDNA analysis. Three Nosema species have been renamed as a result of reports of phylogenetic relatedness. Nosema algerae is now Brachiola algerae (Cali et al. 1998) and Nosema corneum is now Vittaforma corneae (Silveira and Canning 1995). Interestingly, Nosema locustae has been renamed by two different groups. Sokolova et al. (2003) renamed Nosema locustae as Paranosema locustae based on ultrastructure and small subunit rDNA analysis, while Slamovits et al. (2004) renamed Nosema locustae as Antonospora locustae because of its phylogenetic relationship to Antonospora scoticae. Taxonomic divisions which result in polyphyletic clades, as with the true Nosema species and Vairimorpha species, are not acceptable. Generic names within the Nosema and Vairimorpha groups should be determined by phylogenetic placement, with those in the Nosema bombycis clade designated as Nosema species, and those in the Vairimorpha necatrix clade designated as Vairimorpha species. Fig. 1 and other studies (Vossbrinck et al. 2004b) clearly show that the genera Edhazardia, Intrapredatorus and Culicospora fall within the Amblyospora clade and may have to be designated as $\mathrm{Am}$ blyospora in the future. There is an increasing reliance on ssrDNA analysis to determine generic designation (Maddox et al. 1999) and researchers are including ssrDNA sequence analyses as part of their species descriptions (Andreadis and Vossbrinck 2002, Canning et al. 2002, Sokolova et al. 2003).

Small subunit rDNA sequence data for the Microsporidia has been accumulating for nearly two decades, and as the database has grown to include sequences from a large number of taxa, ssrDNA has become the 
Host family Host order

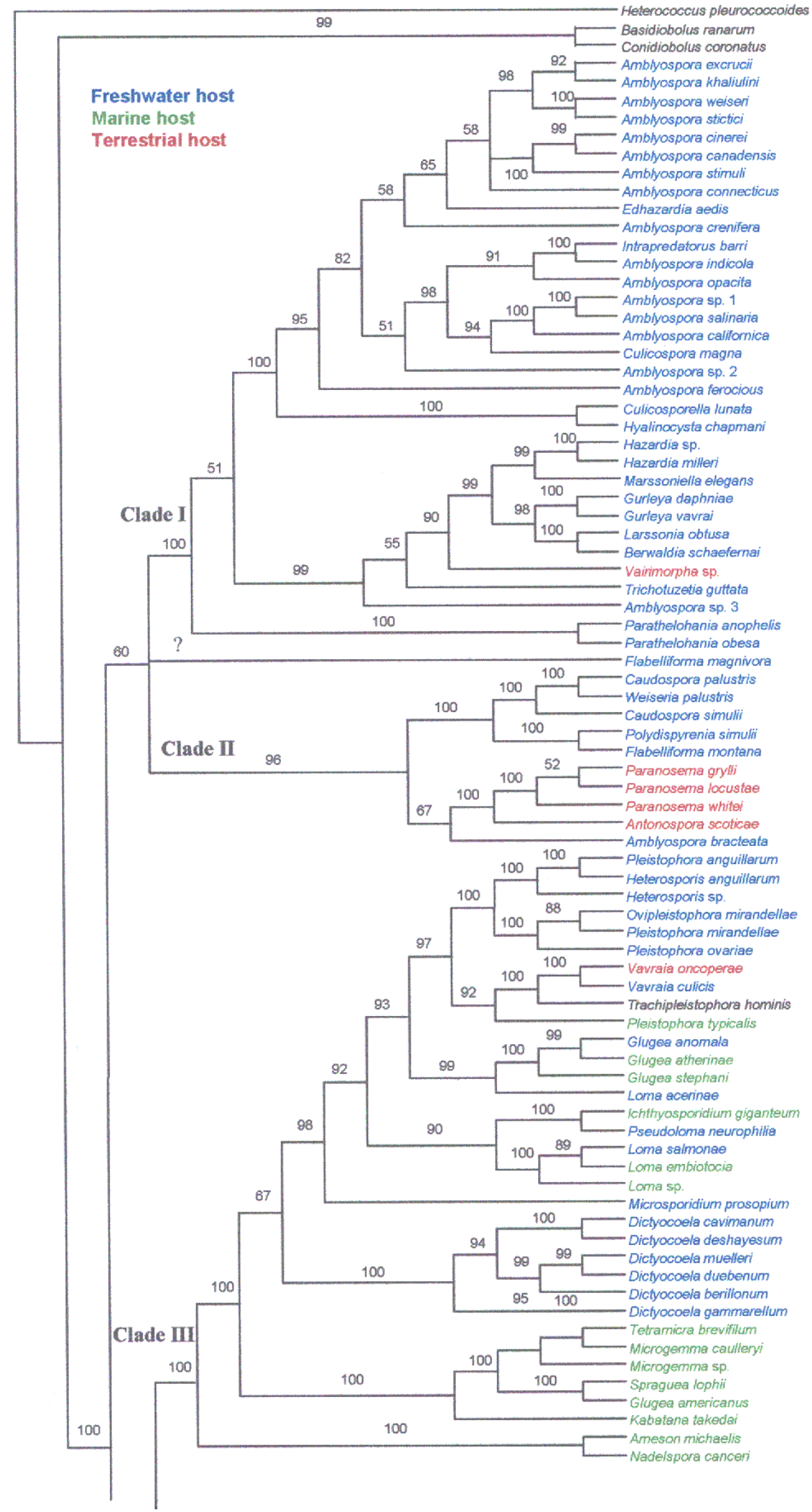

Heteropediaceae Tribonematales Basidiobolacae Entomophthorales Ancylistaceae Entomophthorales

Culicidae Diptera

Culicidae Diptera

Culicidae Diptera

$\begin{array}{ll}\text { Culicidae } & \text { Diptera } \\ \text { Culicidae } & \text { Diptera }\end{array}$

$\begin{array}{ll}\text { Culicidae } & \text { Diptera } \\ \text { Culicidae Diptera } & \end{array}$

Culicidae Diptera

Culicidae Diptera

Culididae Diptera

Culicidae Diptera

Culididae Diptera

Culicidae Diptera

Culicidae Diptera

Culicidae Diptera

Culicidae Diptera

Culicidae Diptera

Culicidae Diptera

Culicidae Diptera

Cyclopidae Cyclopoida

Culicidae Diptera

Culicidae Diptera

Culicidae Diptera

Culicidae Diptera

Culicidae Diptera

Cyclopidae Cyclopoida

Daphniidae Cladocera

Cladocera

Daphniidae Cladocera

Daphniidae Cladocera

Formicidae Hymenoptera

Cyclopidae Cyclopoida

Simullidae Diptera

Culicidae Diptera

Culicidae Diptera

Daphniidae Cladocera

Simuliidae Diptera

Simuliidae Diptera

Simuliidae Diptera

Simuliidae Diptera

Psychodidae Diptera

Gryllidae Orthoptera

Acrididae Orthopter

Tenebrionidae Coleoptera

Andrenidae Hymenoptera

Simuliidae Diptera

Anguilidae Anguilliformes

Anguillidae Anguilliformes

Percidae Perciformes

Cyprinidae Cypriniformes

Cyprinidae Cypriniformes

Cyprinidae Cypriniformes

Hepialidae Lepidoptera

Culicidae Diptera

Coltidae Scorpaeniformes

Gasterosteidae Gasterosteiformes

Atherinidae Atheriniformes

Pleuronectidae Pleuronectiformes

Percidae Perciformes

Sciaenidae Percifomes

Cyprinidae Cypriniformes

Salmonidae Salmoniformes

Embiotocidae Perciformes

Gaidropsaridae Gadiformes

Salmonidae Salmoniformes

Talitridae Amphipoda

Talitidae Amphipoda

Gammaridae Amphipoda

Gammaridae Amphipoda

Gammaridae Amphipoda

Talitridae Amphipoda

Lophiidae Lophiformes

Anguillidae Anguillformes

Cottidae Scorpaeniformes

Lophiidae Lophiiformes

Lophiidae Lophiformes

Salmonidae Salmonifomes

Portunidae Decapoda

Cancridae

Decapoda 


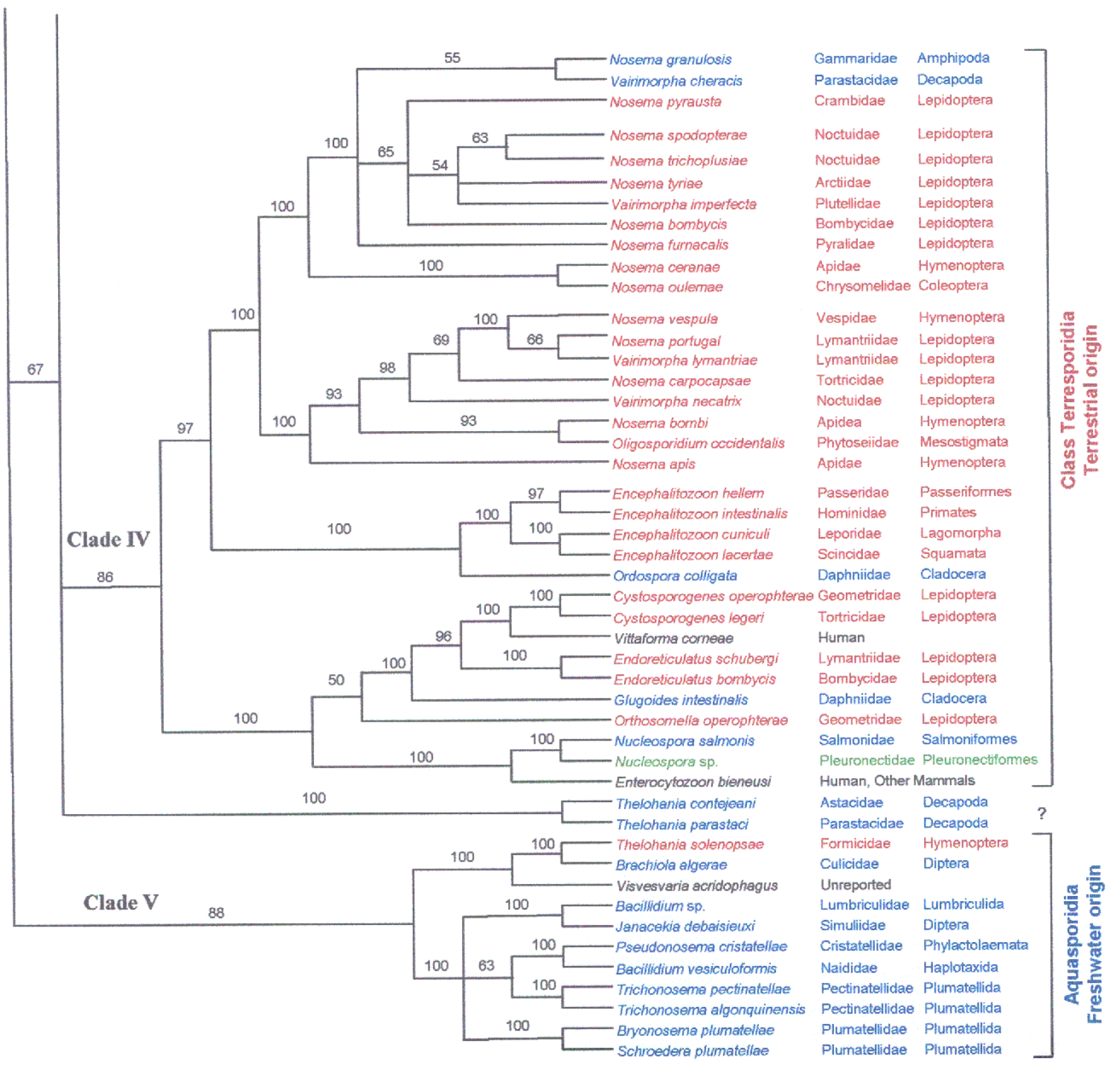

Fig. 1. Bootstrap analysis (25,000 neighbour-joining replicates) of 125 microsporidian isolates and 3 outgroups. Clades I-V are indicated. Microsporidia from freshwater hosts are indicated in blue, from marine hosts in green and from terrestrial hosts in red. Outgroups and microsporidians from human or unreported hosts are in black.

gene of choice for phylogenetic analysis of the Microsporidia. As additional genes are sequenced for a large number of microsporidial species, these new genes may become equal or superior candidates for use in the phylogenetic analysis of the Microsporidia. Various microsporidial genes have been sequenced to explore the phylogenetic placement of the Microsporidia among the eukaryotes (see Weiss and Vossbrinck 1999 for a complete list). These genes include alpha and beta tubulin (Edlind et al. 1996, Keeling and Doolittle 1996), elongation factors 1a/Tu and 2/G (Hashimoto and Hasegawa 1996), RNA polymerase II (Hirt et al. 1999), polar tube protein (Keohane et al. 1998), 5s rRNA (Peyretaillade et al. 1998a), U2 snRNA (DiMaria et al. 1996, Fast et al. 1998), hsp 70 homologue (Peyretaillade et al. 1998b), tRNA synthases (Brown and Doolittle 1995), and chitin synthase (Hinkle et al. 1997). In addition, the genome for Encephalitozoon cuniculi has been sequenced (Katinka et al. 2001) and sequencing of the genome for Paranosema locustae is partially completed (http://jbpc. mbl.edu/Nosema/). This information may help with the selection of likely gene candidates for phylogenetic analysis, by aiding in the search for genes with common microsporidial primers. Cheney et al. (2001) create a phylogeny based on the largest subunit of RNA polymerase II regions $\mathrm{A}-\mathrm{G}$ for 14 species, including those 


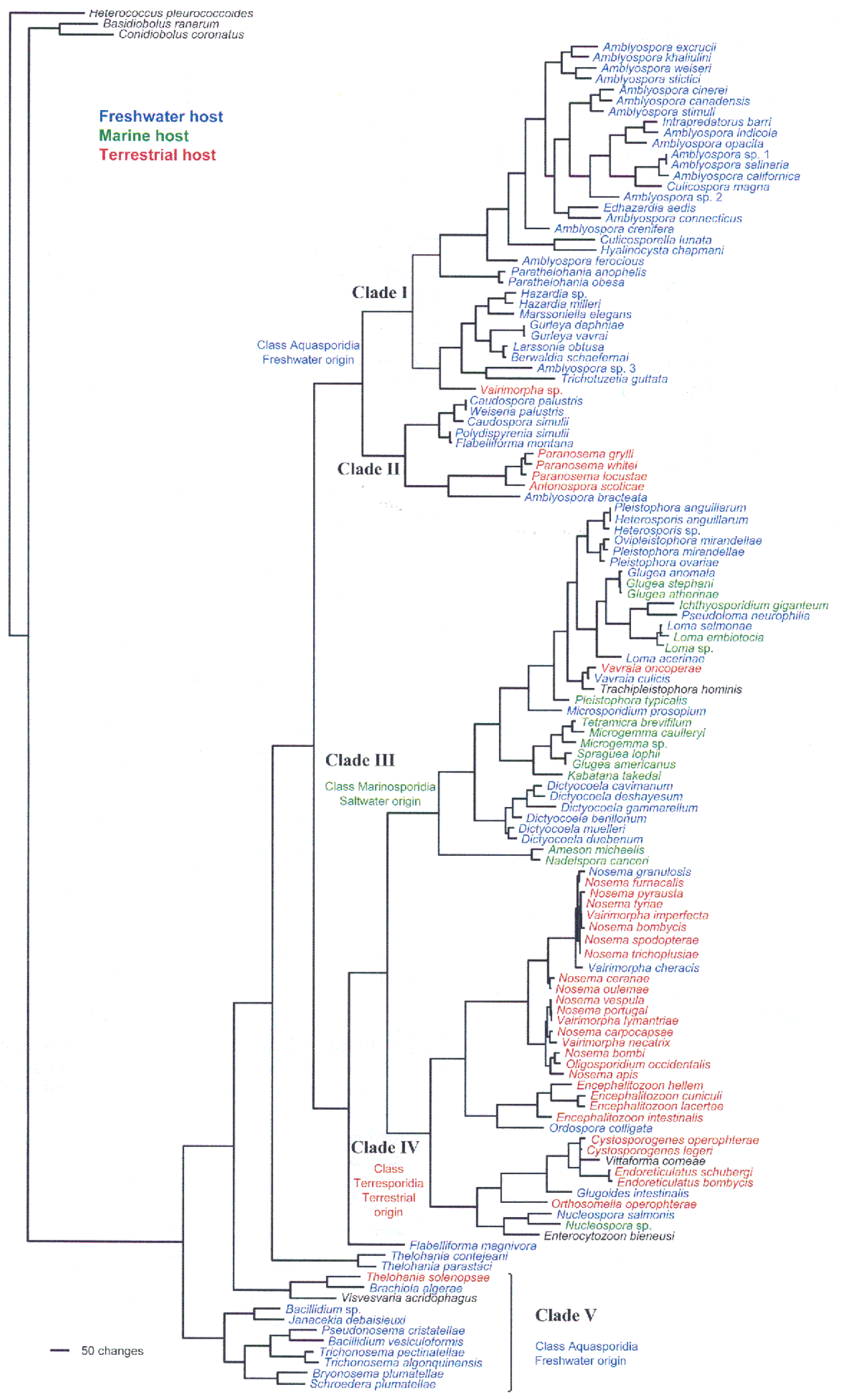


from the marine and terrestrial groups. While much of their phylogeny is in agreement with that shown in Fig. 1 , including the major division between marine and terrestrial Microsporidia (a member of the aquatic group was not available), there are some differences. Spraguea lophii, for example, a parasite of the angler fish Lophius americanus, becomes a member of the terrestrial Microsporidia rather than the marine. Cheney et al. (2001) point out that the largest subunit RNA polymerase II sequence of the species they were working with changes much more rapidly than the ssrDNA. We conclude that the RNA polymerase II gene may be much more useful than ssrDNA for examining relationships at the generic and species levels, but for understanding the basic relationships among the Microsporidia as presented here, ssrDNA may be a better choice. While these studies illustrate that there may not be total phylogenetic agreement among genes, they also highlight the fact that molecular analysis has shown us a tremendous amount about the evolution of the ecological and morphological characters.

\section{Aquatic Microsporidia}

The three most divergent taxa of the Microspordia presented in Figs. 1 and 2, designated here as the Class Aquasporidia, are primarily parasites of freshwater organisms. The Amblyospora, which have complex life cycles, are members of this group. It will be interesting to see if other groups of the Microsporidia have complex life cycles as suggested by Lom and Nilsen (2003) for Microsporidia of marine organisms. The Paranosema species seem to fall within the Aquasporidia. It is possible that the position of Paranosema has not been properly resolved, as indicated by low bootstrap values. It would also appear from Figs. 1 and 2 that one of the clades within the Aquasporidia gave rise to those organisms isolated from hosts of the Marinosporidia and Terresporidia.

\section{Marine Microsporidia}

The majority of the marine Microsporidia, which we designate here as the Class Marinosporidia, represent parasites of marine hosts. Exceptions include parasites of freshwater fish and the Dictyocoela parasites of freshwater amphipods. It could be argued that these Microsporidia were originally parasites of marine organisms whose hosts have adapted to freshwater habitats bringing their parasites with them. The anomalous placements of Vavraia culicis and Vavraia oncoperae cannot be explained so easily, but might represent broad host transfers from marine to freshwater and terrestrial habitats.

\section{Terrestrial Microsporidia}

Isolation of Microsporidia from terrestrial hosts, designated here as the Class Terresporidia, has focused on parasites of insects with economic importance. The Nosema/Vairimorpha group parasitize many Lepidoptera as well as Hymenoptera and Coleoptera. The Encephalitozoon species represent a taxonomically based clade isolated exclusively from vertebrates (Wright and Craighead 1922) including mammals, birds and reptiles (Koudela et al. 1998). The clade containing Cystosporogenes and Endoreticulatus represents organisms which infect insects. Vittaforma corneae falls within this clade, but was isolated from humans. It has been speculated that Vittaforma corneae is not a true human parasite, and that its isolation from humans represents an opportunistic infection. New research indicates that a number of Nosema/Vairimorpha species are parasites of aquatic hosts (Terry et al. 1999, Moodie et al. 2003), which may require adjustment of the taxonomy presented here. Based on Figs. 1 and 2, one might hypothesize that Nosema granulosis and Vairimorpha cheracis are two related Nosema species which have evolved from terrestrial Microsporidia. It is possible that other aquatic hosts may be found for members of this group of parasites isolated primarily from terrestrial hosts.

Flabelliforma magnivora and two Thelohania species (T. parastaci and T. contejeani) are also unresolved and will perhaps be resolved in the future after further analysis.

\section{Conclusion}

Five major clades with three taxonomic (class) designations in the phylum Microsporidia are identified in the phylograms in Figs. 1 and 2. Assuming a reasonable sequence alignment, the similarities between the neighbour-joining analysis of Fig. 1 and the parsimony analysis of Fig. 2 indicate a fair degree of certainty concerning the relationships among the major groups of Microsporidia presented here. We now see a much clearer picture of the correlation between host and parasite (see host taxa as indicated in Fig. 1). Traditional classification schemes (Sprague 1977) often group together species isolated from disparate hosts. Molecular phylogenetic analysis has revealed that genera such as Nosema, Vairimorpha, Amblyospora, Thelohania and Pleistophora are polyphyletic in origin, and efforts are being made to reclassify species unrelated to the type species. It has been proposed that the complex life cycle which involves an obligate intermediate host is an ancestral condition and therefore may exist in all groups of Microsporidia (Baker et al. 1997). As derived fungi,

Fig. 2. Maximum parsimony analysis of 125 microsporidian isolates and 3 outgroups using the heuristic search method (one of 30 trees at 13,468 steps). Clades I-V are indicated. The trees generated differed in the relationships among the Nosema/Vairimorpha group, and to a small extent, in the relationships among the Dictyocoela species. The main branching patterns remained the same for all 30 trees. Microsporidia from freshwater hosts are indicated in blue, from marine hosts in green and from terrestrial hosts in red. Outgroups and microsporidians from human or unreported hosts are in black. 
perhaps microsporidia such as Nosema species, defined as being diplokaryotic throughout their life cycle, represent organisms which have lost their ability to produce gametes (uninucleate spores). Pleistophora, which are uninucleate throughout their life cycle, may represent organisms for which the definitive host has been lost from the life cycle.

We are at an exciting time in the study of the phylogeny and taxonomy of the Microsporidia. Studies (Edlind et al. 1996, Keeling and Doolittle 1996) showing the Microsporidia to be derived fungi have resulted in the inclusion of more appropriate outgroups for the analysis of phylogeny within the Microsporidia (Canning et al. 2002, Refardt et al. 2002). Over the past decade it has become increasingly apparent that diplokaryotic and uninucleate stages can be lost or gained very rapidly over evolutionary time in response to environmental circumstances such as the lack of an intermediate host, or even due to the effect of temperature on development in the case of Vairimorpha species (Malone and McIvor 1996). In short, the characters used to distinguish among the higher taxonomic levels of the Microsporidia change state very rapidly and taxonomies based on these characters result in unacceptable polyphyletic clades (clades which are defined by character states which have evolved separately many times and are not characteristic of a common ancestor).

Neither the taxonomic designations given here nor the phylogeny presented in Figs. 1 and 2 represent a final classification. We have included only 125 of the more than 1,200 known species of Microsporidia (Wittner 1999) in our analysis. Many described genera are not included in this phylogeny, and there may be many genera yet undescribed. The Metchnikovellidae, Chytridiopsidae and Hessidae, possible microsporidial outgroups, have not been sequenced. As discussed earlier, several researchers have found true Nosema species in aquatic crustaceans, which may necessitate changes in the taxonomy proposed here. In addition further analysis may be needed for rooting the microsporidial tree. Nonetheless, the phylogeny described here reveals a number of relationships among the Microsporidia which were unknown prior to the use of comparative rDNA sequence analysis. Grouping the Microsporidia into classes based on habitat (Aquasporidia, Marinosporidia, Terresporidia) appears more consistent with evolutionary relationships than do previously proposed schemes for higher level classification based on morphology and life-cycle characters.

\section{REFERENCES}

ANDREADIS T.G. 1985: Life cycle, epizootiology, and horizontal transmission of Amblyospora (Microspora: Amblyosporidae) in a univoltine mosquito, Aedes stimulans. J. Invertebr. Pathol. 46: 31-46.

ANDREADIS T.G., VOSSBRINCK C.R. 2002: Life cycle, ultrastructure and molecular phylogeny of Hyalinocysta chapmani (Microsporidia: Thelohaniidae), a parasite of Culiseta melanura (Diptera: Culicidae) and Orthocyclops modestus (Copepoda: Cyclopidae). J. Eukaryot. Microbiol. 49: $350-364$.

BAKER M.D., VOSSBRINCK C.R., BECNEL J.J., ANDREADIS T.G. 1998: Phylogeny of Amblyospora (Microsporida, Amblyosporidae) and related genera based on small subunit ribosomal DNA data: a possible example of host parasite cospeciation. J. Invertebr. Pathol. 71: 199206.

BAKER M.D., VOSSBRINCK C.R., BECNEL J.J., MADDOX J.V. 1997: Phylogenetic position of Amblyospora Hazard and Oldacre (Microspora, Amblyosporidae) based on small subunit rRNA data and its implication for the evolution of the Microsporidia. J. Eukaryot. Microbiol. 44: 220-225.

BAKER M.D., VOSSBRINCK C.R., DIDIER E.S., MADDOX J.V., SHADDUCK J.A. 1995: Small subunit ribosomal DNA phylogeny of various Microsporidia with emphasis on AIDS related forms. J. Eukaryot. Microbiol. 42: 564-570.

BAKER M.D., VOSSBRINCK C.R., MADDOX J.V., UNDEEN A.H. 1994: Phylogenetic relationships among Vairimorpha and Nosema species (Microspora) based on ribosomal RNA sequence data. J. Invertebr. Pathol. 64: 100-106.

BALBIANI G. 1882: Sur les microsporidies ou psorospermies des articules. C. R. Acad. Sci. 95: 1168-1171.

BROWN J.R., DOOLITTLE W.F. 1995: Root of the universal tree of life based on ancient aminoacyl-tRNA synthetase gene duplications. Proc. Natl. Acad. Sci. USA. 92: 24412445.

CALI A., TAKVORIAN P.M., LEWIN S., RENDEL M., SIAN C.S., WITTNER M., TANOWITZ H.B., KEOHANE E., WEISS L.M. 1998: Brachiola vesicularum, n. g., n. sp., a new microsporidium associated with AIDS and myositis. J. Eukaryot. Microbiol. 45: 240-251.

CANNING E.U., REFARDT D., VOSSBRINCK C.R., OKAMURA B., CURRY A. 2002: New diplokaryotic microsporidia (Phylum Microsporidia) from freshwater bryozoans (Bryozoa, Phylactolaemata). Eur. J. Protistol. 38: 247-265.

CHENEY S.A., LAFRANCHI-TRISTEM N.J., BOURGES D., CANNING E.U. 2001: Relationships of microsporidian genera, with emphasis on the polysporous genera, revealed by sequences of the largest subunit of RNA polymerase II (RPB1). J. Eukaryot. Microbiol. 48: 111-117.

DIDIER E.S., DIDIER P.J., FRIEDBERG D.N., STENSON S.M., ORENSTEIN J.M., YEE R.W., TIO F.O., DAVIS R.M., VOSSBRINCK C.R., MILLICHAMP N., SHADDUCK J.A. 1991: Isolation and characterization of a new human microsporidian, Encephalitozoon hellem (n. sp.) from three AIDS patients with keratoconjunctivitis. J. Infect. Dis. 163: 617-621. 
DIDIER E.S., VISVESVARA G.S., BAKER M.D., ROGERS L.B., BERTUCCI D.C., DE GROOTE M.A., VOSSBRINCK C.R. 1996: A microsporidian isolated from an AIDS patient corresponds to Encephalitozoon cuniculi III, originally isolated from domestic dogs. J. Clin. Microbiol. 34: 2835-2837.

DiMARIA P., PALIC B., DEBRUNNER-VOSSBRINCK B.A., LAPP J., VOSSBRINCK C.R. 1996: Characterization of the highly divergent U2 RNA homolog in the microsporidian Vairimorpha necatrix. Nucl. Acids Res. 24: 515-522.

EDLIND T.D., LI J., VISVESVARA G.S., VODKIN M.H., McLAUGHLIN G.L., KATIYAR S.K. 1996: Phylogenetic analysis of beta-tubulin sequences from amitochondrial protozoa. Mol. Phylogenet. Evol. 5: 359-367.

FAST N.M., ROGER A.J., RICHARDSON C.A., DOOLITTLE W.F. 1998: U2 and U6 snRNA genes in the microsporidian Nosema locustae - evidence for a functional spliceosome. Nucl. Acids Res. 26: 3202-3207.

FELSENSTEIN J. 1981: Evolutionary trees from DNA sequences: a maximum likelihood approach. J. Mol. Evol. 17: $368-376$

HASHIMOTO T., HASEGAWA M. 1996: Origin and early evolution of eukaryotes inferred from the amino acid sequences of translation elongation factors $1 \alpha / \mathrm{Tu}$ and $2 / \mathrm{G}$. Adv. Biophys. 32: 73-120.

HENNIG W. 1966: Phylogenetic Systematics. University of Illinois Press, Urbana, Chicago, London, 280 pp.

HINKLE G., MORRISON H.G., SOGIN M.L. 1997: Genes coding for reverse transcriptase, DNA-directed RNA polymerase, and chitin synthase from the microsporidian Spraguea lophii. Biol. Bull. 193: 250-251.

HIRT R.P., LOGSDON J.M., HEALY B., DOREY M.W., DOOLITTLE W.F., EMBLEY T.M. 1999: Microsporidia are related to Fungi: evidence from the largest subunit of RNA polymerase II and other proteins. Proc. Natl. Acad. Sci. USA 96: 580-585.

HUELSENBECK J.P., RONQUIST F., NIELSEN R., BOLLBACK J.P. 2001: Bayesian inference of phylogeny and its impact on evolutionary biology. Science 294: 2310-2314.

ISSI I.V. 1986: Microsporidia as a phylum of parasitic protozoa. Protozoology (Leningrad) 10: 1-136.

KATINKA M.D., DUPRAT S., CORNILLOT E., MÉTÉNIER G., THOMARAT F., PRENSIER G., BARBE V., PEYRETAILLADE E., BROTTIER P., WINCKER P., DELBAC F., El ALAOUI H., PEYRET P., SAURIN W., GOUY M., WEISSENBACH J., VIVARÈS C.P. 2001: Genome sequence and gene compaction of the eukaryote parasite Encephalitozoon cuniculi. Nature 414: 450-453.

KEELING P.J., DOOLITTLE W.F. 1996: Alpha-tubulin from early-diverging eukaryotic lineages and the evolution of the tubulin family. Mol. Biol. Evol. 13: 1297-1305.

KEELING P.J., LUKER M.A., PALMER J.D. 2000: Evidence from beta-tubulin phylogeny that Microsporidia evolved from within the fungi. Mol. Biol. Evol. 17: 23-31.

KENT M.L., HERVIO D.M., DOCKER M.F., DEVLIN R.H. 1996: Taxonomy studies and diagnostic tests for myxosporean and microsporidian pathogens of salmonid fishes utilising ribosomal DNA sequence. J. Eukaryot. Microbiol. 43: 98S-99S.
KEOHANE E.M., ORR G.A., ZHANG H.S., TAKVORIAN P.M., CALI A., TANOWITZ H.B., WITTNER M., WEISS L.M. 1998: The molecular characterization of the major polar tube protein gene from Encephalitozoon hellem, a microsporidian parasite of humans. Mol. Biochem. Parasitol. 94: 227-236.

KOUDELA B., DIDIER E.S., ROGERS L.B., MODRÝ D., KUČEROVÁ S. 1998: Intestinal microsporidiosis in African skink Mabuya perrotetii. Folia Parasitol. 45: 149-155.

LARSSON R. 1986: Ultrastructure, function, and classification of Microsporidia. Progr. Protistol. 1: 325-390.

LARSSON J.I.R. 1988: Identification of microsporidian genera (Protozoa, Microspora) - a guide with comments on the taxonomy. Arch. Protistenkd. 136: 1-37.

LARSSON J.I.R. 1999: Identification of Microsporidia. Acta Protozool. 38: 161-197.

LÉGER L., HESSE E. 1922: Microsporidies bactériformes et essai de sytematique du groupe. C. R. Acad. Sci. 174: 327-330.

LOM J., NILSEN F. 2003. Fish microsporidia: fine structural diversity and phylogeny. Int. J. Parasitol. 33: 107-127.

MADDOX J.V., BAKER M.D., JEFFORDS M.R., KURAS M., LINDE A., SOLTER L.F., McMANUS M.L., VÁVRA J., VOSSBRINCK C.R. 1999: Nosema portugal, n. sp., isolated from gypsy moths (Lymantria dispar L.) collected in Portugal. J. Invertebr. Pathol. 73: 1-14.

MALONE L.A., McIVOR C.A. 1996: Use of nucleotide sequence data to identify a microsporidian pathogen of Pieris rapae (Lepidoptera, Pieridae). J. Invertebr. Pathol. 68: 231-238.

MOODIE E.G., Le JAMBRE L.F., KATZ M. 2003: Ultrastructural characteristics and small subunit ribosomal DNA sequence of Vairimorpha cheracis sp. nov., (Microspora: Burenellidae), a parasite of the Australian yabby, Cherax destructor (Decapoda: Parastacidae). J. Invertebr. Pathol. 84: 198-213.

MURPHY W.J., EIZIRIK E., O'BRIEN S.J., MADSEN O., SCALLY M., DOUADY C.J., TEELING E., RYDER O.A., STANHOPE M.J., de JONG W.W., SPRINGER M.S. 2001: Resolution of the early placental mammal radiation using Bayesian phylogenetics. Science 294: 22662268.

PEYRETAILlADE E., BIDERRE C., PEYRET P., DUFFIEUX F., METENIER G., GOUY M., MICHOT B., VIVARES C.P. 1998a: Microsporidian Encephalitozoon cuniculi, a unicellular eukaryote with an unusual chromosomal dispersion of ribosomal genes and a lsu rRNA reduced to the universal core. Nucl. Acids Res. 26: 35133520.

PEYRETAILLADE E., BROUSSOLLE V., PEYRET P., MÉTÉNIER G., GOUY M., VIVARÈS C.P. 1998b: Microsporidia, amitochondrial protists, possess a $70-\mathrm{kDa}$ heat shock protein gene of mitochondrial evolutionary origin. Mol. Biol. Evol. 15: 683-689.

REFARDT D., CANNING E.U., MATHIS A., CHENEY S.A., LAFRANCHI-TRISTEM N.J., EBERT D. 2002: Small subunit ribosomal DNA phylogeny of Microsporidia that infect Daphnia (Crustacea: Cladocera). Parasitology 124: 381-389. 
SILVEIRA H., CANNING E.U. 1995: Vittaforma corneae $\mathrm{n}$. comb. for the human microsporidium Nosema corneum Shadduck, Meccoli, Davis \& Font, 1990, based on its ultrastructure in the liver of experimentally infected athymic mice. J. Eukaryot. Microbiol. 42: 158-165.

SLAMOVITS C.H., WILLIAMS B.A.P., KEELING P.J. 2004: Transfer of Nosema locustae (Microsporidia) to Antonospora locustae $\mathrm{n}$. comb. based on molecular and ultrastructural data. J. Eukaryot. Microbiol. 51: 207-213.

SOKOLOVA Y.Y., DOLGIKH V.V., MORZHINA E.V., NASSONOVA E.S., ISSI I.V., TERRY R.S., IRONSIDE J.E., SMITH J.E., VOSSBRINCK C.R. 2003: Establishment of the new genus Paranosema based on the ultrastructure and molecular phylogeny of the type species Paranosema grylli Gen. Nov., Comb. Nov. (Sokolova, Selezniov, Dolgikh, Issi 1994), from the cricket Gryllus bimaculatus Deg. J. Invertebr. Pathol. 84: 159-172.

SPRAGUE V. 1982: Microspora. In: S.P. Parker (Ed.), Synopsis and Classification of Living Organisms. McGrawHill, New York, pp. 589-594.

SPRAGUE V., BECNEL J.J., HAZARD E.I. 1992: Taxonomy of phylum Microspora. Crit. Rev. Microbiol. 18: 285-395.

SPRAGUE V. 1977: Classification and Phylogeny of the Microsporidia. In: L.A. Bulla and T.C. Cheng (Eds.), Comparative Pathobiology. Vol. 2. Plenum Press, New York, pp. 1-30.

STEMPELL W. 1909: Ueber Nosema bombycis Naegeli. Arch. Protistenkd. 16: 281-358.

SWEENEY A.W., HAZARD E.I., GRAHAM M.F. 1985: Intermediate host for an Amblyospora sp. (Microspora) infecting the mosquito Culex annulirostris. J. Invertebr. Pathol. 46: 98-120.

SWOFFORD D. 2002: Phylogenetic analysis using parsimony: and other methods. Version 4.0 Beta Version of the Command Manual for PAUP. Sinauer Associates, Sunderland, MA.

TERRY R.S., SMITH J.E., BOUCHON D., RIGAUD T., DUNCANSON P., SHARPE R.G., DUNN A.M. 1999: Ultrastructural characterization and molecular taxonomic identification of Nosema granulosis n. sp., a transovarially transmitted feminizing (TTF) microsporidium. J. Eukaryot. Microbiol. 46: 492-499.

TUZET O., MAURAND J., FIZE J.A., MICHEL R., FENWICK B. 1971: Proposition d'un nouveau cadre systematique pour les genres de Microsporidies. C. R. Acad. Sci. (Paris) 272: 1268-1271.

VOSSBRINCK C.R., ANDREADIS T.G., DEBRUNNERVOSSBRINCK B.A. 1998: Verification of intermediate hosts in the life cycles of Microsporidia by small subunit rDNA sequencing. J. Eukaryot. Microbiol. 45: 290-292.

VOSSBRINCK C.R., ANDREADIS T.G., VÁVRA J., BECNEL J.J. 2004b: Molecular phylogeny and evolution of mosquito parasitic Microsporidia (Microsporidia: Amblyosporidae). J. Eukaryot. Microbiol. 51: 88-95.

VOSSBRINCK C.R., ANDREADIS T.G., WEISS L.M. 2004a: Phylogenetics: taxonomy and the Microsporidia as derived fungi. In: D.S. Lindsay and L.M. Weiss (Eds.), World Class Parasites: Volume 9, Opportunistic Infections: Toxoplasma, Sarcocystis and Microsporidia. Kluwer Academic Publishers, Boston, pp. 189-215.

VOSSBRINCK C.R., BAKER M.D., DIDIER E.S., DEBRUNNER-VOSSBRINCK B.A., SHADDUCK J.A. 1993: Ribosomal DNA sequences of Encephalitozoon hellem and Encephalitozoon cuniculi: species identification and phylogenetic construction. J. Eukaryot. Microbiol. 40: 354-362.

WEISER J. 1977: Contribution to the classification of Microsporidia. Vestn. Cesk. Spol. Zool. 41: 308-320.

WEISS L.M., VOSSBRINCK C.R. 1999: Molecular biology, molecular phylogeny, and molecular diagnostic approaches to the Microsporidia. In: M. Wittner and L.M. Weiss (Eds.), The Microsporidia and Microsporidiosis. ASM Press, Washington, D.C., pp. 129-171.

WITTNER M. 1999: Historic perspectives on the Microsporidia: expanding horizons. In: M. Wittner and L.M. Weiss (Eds.), The Microsporidia and Microsporidiosis. ASM Press, Washington, D.C., pp. 1-6.

WRIGHT J.H., CRAIGHEAD E.M. 1922: Infectious motor paralysis in young rabbits. J. Exp. Med. 36: 135-140. 